\title{
Spontaneous Complete Uterine Rupture in a Nonlaboring, Early Third-trimester Uterus: Missed Diagnosis by Ultrasound
}

\author{
Luke Dixon, MD $^{1} \quad$ S. J. Carlan, MD ${ }^{1} \quad$ T. D. O'Leary, $M^{1} \quad$ Jose Perez, MD² \\ ${ }^{1}$ Department of Obstetrics and Gynecology, Winnie Palmer Hospital, \\ Orlando Regional Healthcare, Orlando, Florida \\ Address for correspondence S. J. Carlan, MD, 105 West Miller Street, \\ Orlando, FL 32806 (e-mail: stevecarlan@gmail.com).
}

2 Division of Neonatology, Winnie Palmer Hospital, Orlando Regional Healthcare, Orlando, Florida

\begin{abstract}
Keywords

- uterine rupture

- third trimester

- spontaneous

- fetal auscultation
\end{abstract}

Complete rupture of a pregnant uterus is a catastrophic obstetric event with a high maternal and perinatal complication rate. Spontaneous uterine rupture in a nonlaboring patient with an unscarred and congenitally normal uterus at the beginning of the third trimester is exceedingly rare. We present a case of spontaneous third-trimester uterine rupture with complete expulsion of the fetus and placenta into the abdomen that evolved as the patient was observed.

\section{Case Report}

A 30-year-old G20010 presented at 2:40 Am at 28 weeks' gestation complaining of intermittent periumbilical and mild epigastric pain for 1 day. On arrival to our hospital, she had 10/ 10 right lower quadrant pain aggravated by lying down. She denied abdominal trauma, chills, fever, nausea, anorexia, vomiting, or vaginal bleeding. Her pregnancy to that point had been uneventful. A previous second-trimester ultrasound had been reported as normal. Her physical examination was normal other than tenderness to palpation in the right lower quadrant. Her cervix was closed, thick, firm, and posterior. The fetal heart tracing was reassuring with no signs of fetal compromise and no contractions were noted. The patient reported a surgical history solely consisting of diagnostic laparoscopy for infertility and endometriosis and an uncomplicated dilation and curettage for a previous early spontaneous abortion. The initial working diagnosis was appendicitis versus ovarian torsion and laboratories and imaging were ordered. A fetal ultrasound at 3:30 Am showed a viable 29-week intrauterine pregnancy in the cephalic position with a possible synechiae measuring $1.8 \mathrm{~cm}$ thick (-Fig. 1). The placenta was posterior. The patient's coagulation studies including fibrinogen returned normal and her hemoglobin was stable at $11.9 \mathrm{~g} / \mathrm{dL}$. received

January 29, 2013 accepted after revision

February 8, 2013

published online

March 19, 2013
DOI http://dx.doi.org/

10.1055/s-0033-1341575. ISSN 2157-6998.
Copyright (c 2013 by Thieme Medical Publishers, Inc., 333 Seventh Avenue, New York, NY 10001, USA. Tel: +1(212) 584-4662.
License terms

(요 (1) $\Theta \circledast$ 


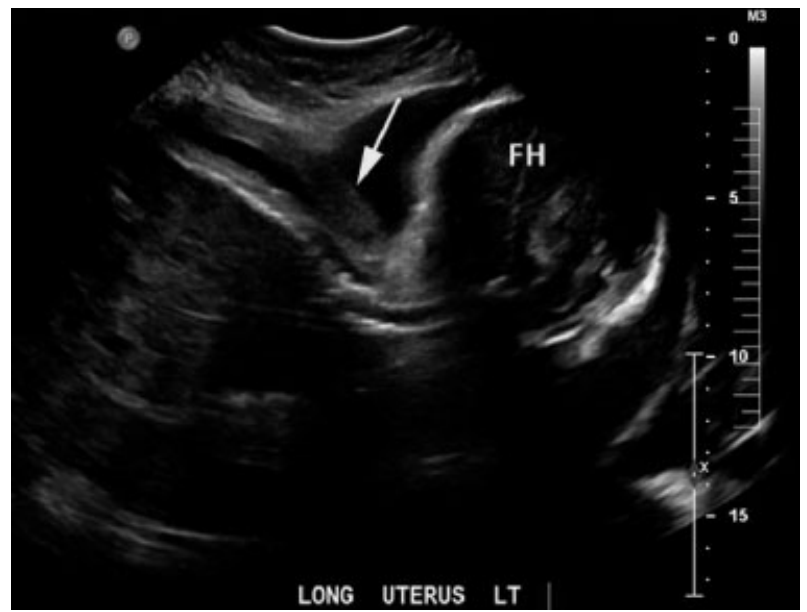

Fig. 1 First ultrasound on arrival. Arrow denotes the reported synechiae. Abbreviation: FH, fetal head; LT, left.

Due to continued pain an abdominal-pelvic computed tomography (CT) scan with contrast was performed at 4:57 Am. After returning from radiology at 5:20 Am, the fetus was found to have low heart tones in the 80s to $90 \mathrm{~s}$, and locating fetal heart tones was difficult. A bedside ultrasound showed free fluid in the posterior cul-de-sac and the radiologist who read the CT scan communicated with the attending that the fetus was in the abdomen (-Fig. 2). An emergency laparotomy was then performed at 05:47 AM, which revealed both the placenta and fetus floating free outside of the uterus. There was a uterine defect noted in the lower uterine segment anteriorly measuring $6 \times 4 \mathrm{~cm}$, which was closed.

The female infant weighed 2 pounds 12 ounces and had an umbilical artery cord $\mathrm{pH}$ of 6.74 and a base deficit of 22.3. Apgar scores were noted to be 0 ( 1 minute), 4 (5 minutes), 6 (10 minutes), and 7 (15 minutes). Maternal estimated blood

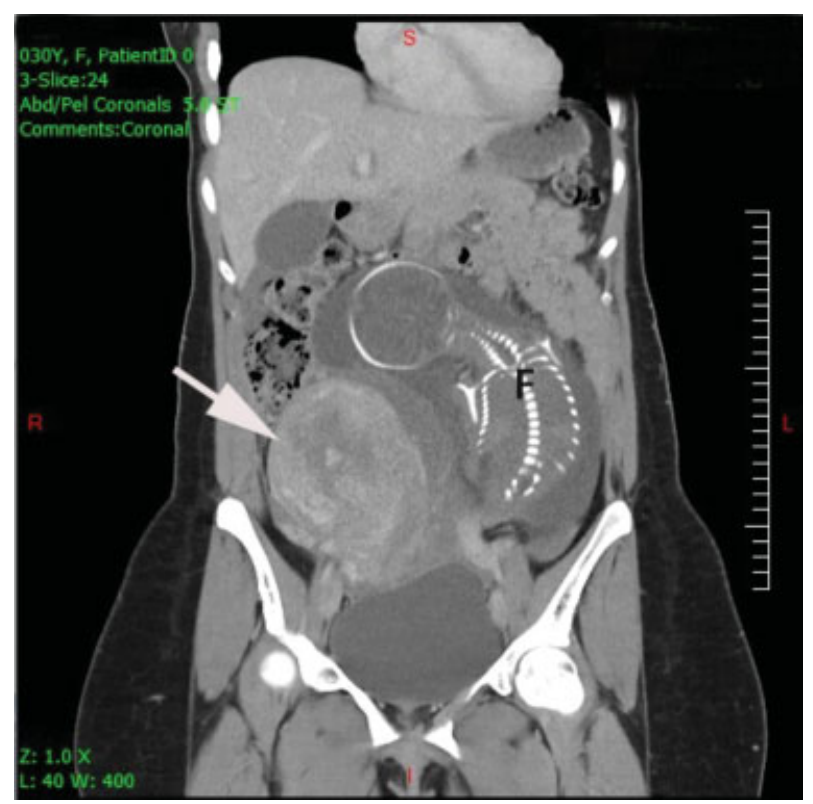

Fig. 2 Computed tomography of the abdomen after the uterine rupture. Arrow denotes the empty uterus. Abbreviation: F, fetus. loss for the entire case was $2 \mathrm{~L}$. The patient then underwent an uncomplicated postoperative course and was discharged home on postoperative day 4 . The infant was discharged on day of life 70 with a grade III intraventricular hemorrhage and seizures.

\section{Discussion}

The process of the dehiscence leading to the rupture probably began hours prior to admission when she began having pain. In fact, on reviewing the first ultrasound image it appears that the originally diagnosed synechiae was the edge of the uterine defect and the fetal head was already extruded through the hole. Not only did the misdiagnosis of the rupture lead to a delay, but labeling the uterine defect a synechiae gave the obstetric team a reason for the abnormal image, delaying the diagnosis even more.

Uterine synechiae can follow uterine curettage, but they are not known to be a risk factor for spontaneous obstetric uterine rupture unless they are treated surgically. ${ }^{1}$ Also, the patient did have a history of uterine curettage and there is a reported uterine perforation rate of 19.8 per 1,000 at the time of dilatation and curettage when laparoscopy is used to evaluate the uterine fundus. ${ }^{2}$ Because a perforation results in a scar and a scar is a risk for obstetric rupture, it is conceivable she had a perforation even though her curettage was uncomplicated and a uterine wall defect was not seen during her second-trimester ultrasound. Other than the remote possibility of an unknown uterine scar from an unconfirmed perforation at the time of curettage, she had no known risk factors for uterine rupture. Most frequently, uterine rupture is related to prior cesarean section. ${ }^{3,4}$ Regardless of the ultrasound report, the rupture was present and the diagnosis missed. The report should always document that the fetus is in the uterus, and the presenting part is within the lower uterus and/or birth canal. The maternal bladder should always be visualized just above the presenting part.

This case illustrates the consequences of both diagnostic tunnel vision and the morbidity of delay. Because the patient had no clear risk factors for uterine rupture and all obstetric diagnostic elements were normal, the clinical team eliminated the possibility of uterine dehiscence and impending rupture as the cause of the pain. Supporting the decision to eliminate the most serious possible cause of the pain are the data suggesting that the incidence of rupture of an unscarred uterus is estimated to be $1 / 8,000$ to $1 / 15,000$ deliveries. $^{5}$

The poor condition of the newborn at birth illustrates the morbidity of delay. The length of time of fetal oxygen deprivation is directly related to the baby's respiratory and metabolic status, ${ }^{6}$ and the decline in oxygen and buffer base occurs rapidly during acute, severe fetal compromise. ${ }^{7}$ This baby had severe hypoxic-induced metabolic acidemia that could have been avoided if the fetal compromise were recognized earlier. $^{8}$

The unfortunate coincidence of the rupture occurring at the time she was off of the fetal monitor resulted in a significant delay in diagnosis and thus delivery. 
The lessons learned from this case include a continued awareness of the possibility, no matter how remote, of a potential impending uterine rupture when a pregnant woman presents with persistent unexplained abdominal pain. The classic finding of an early ruptured uterus is fetal compromise and diagnosing fetal compromise requires monitoring. Intermittent fetal heart tone auscultation while the patient is off continuous monitoring should have been performed and should be standard. Even with the misdiagnosis of the rupture, intermittent auscultation could have resulted in the patient's immediate return to triage.

In summary, there have been 35 reported cases of rupture of the primigravid uterus in the literature in the past 60 years, 10 of which have been reported from the years 2000 to $2007 .^{9}$ This case represents the earliest known spontaneous rupture with a living newborn in a patient with no known risk factors. The case is unique in that the rupture's evolution was documented by "before-and-after" imaging and confirmed at laparotomy. The case is instructive because it illustrates that a very simple and low-cost method of monitoring, intermittent fetal heart tone auscultation with a doptone while she was off continuous fetal monitoring, could have changed the condition of the newborn at birth. Also, radiologists should note this condition as soon as the images show up on their screen.

\section{References}

1 Yu D, Wong YM, Cheong Y, Xia E, Li TC. Asherman syndrome-one century later. Fertil Steril 2008;89:759-779

2 Dow M, Wax JR, Pinette MG, Blackstone J, Cartin A. Thirdtrimester uterine rupture without previous cesarean: a case series and review of the literature. Am J Perinatol 2009;26: 739-744

3 Langton J, Fishwick K, Kumar B, Nwosu EC. Spontaneous rupture of an unscarred gravid uterus at 32 weeks gestation. Hum Reprod 1997; 12:2066-2067

4 Chigbu B, Onwere S, Kamanu C, Aluka C, Adibe E, Onichakwe C. Rupture of the uterus in a primigravida: a case report. Niger J Clin Pract 2010;13:233-234

5 Singh A, Jain S. Spontaneous rupture of unscarred uterus in early pregnancy-a rare entity. Acta Obstet Gynecol Scand 2000;79: 431-432

6 Jain L, Ferre C, Vidyasagar D, Nath S, Sheftel D. Cardiopulmonary resuscitation of apparently stillborn infants: survival and longterm outcome. J Pediatr 1991;118:778-782

7 Ross MG, Gala R. Use of umbilical artery base excess: algorithm for the timing of hypoxic injury. Am J Obstet Gynecol 2002;187:1-9

8 Low JA, Lindsay BG, Derrick EJ. Threshold of metabolic acidosis associated with newborn complications. Am J Obstet Gynecol 1997;177:1391-1394

9 Walsh CA, Baxi LV. Rupture of the primigravid uterus: a review of the literature. Obstet Gynecol Surv 2007;62:327-334, quiz 353-354 